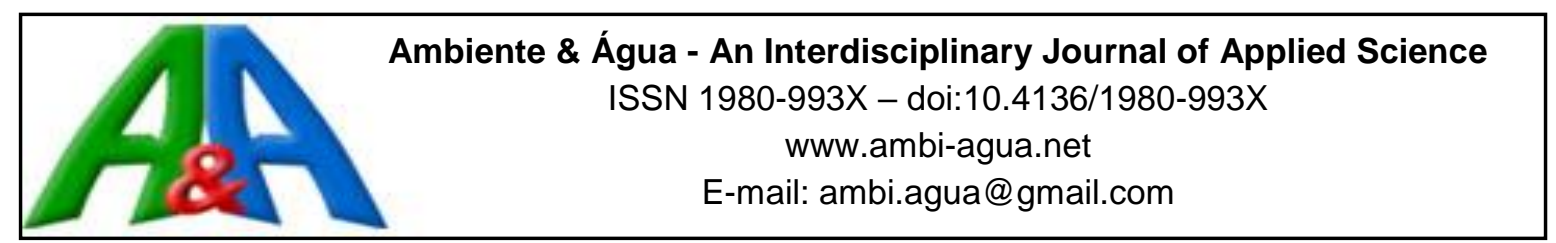

\title{
Crescimento foliar e atividades das enzimas antioxidativas em plântulas de girassol suplementadas com percolado de aterro sanitário e submetidas a estresse hídrico
}

\author{
doi:10.4136/ambi-agua.1964
}

Received: 30 Jun. 2016; Accepted: 26 Oct. 2016

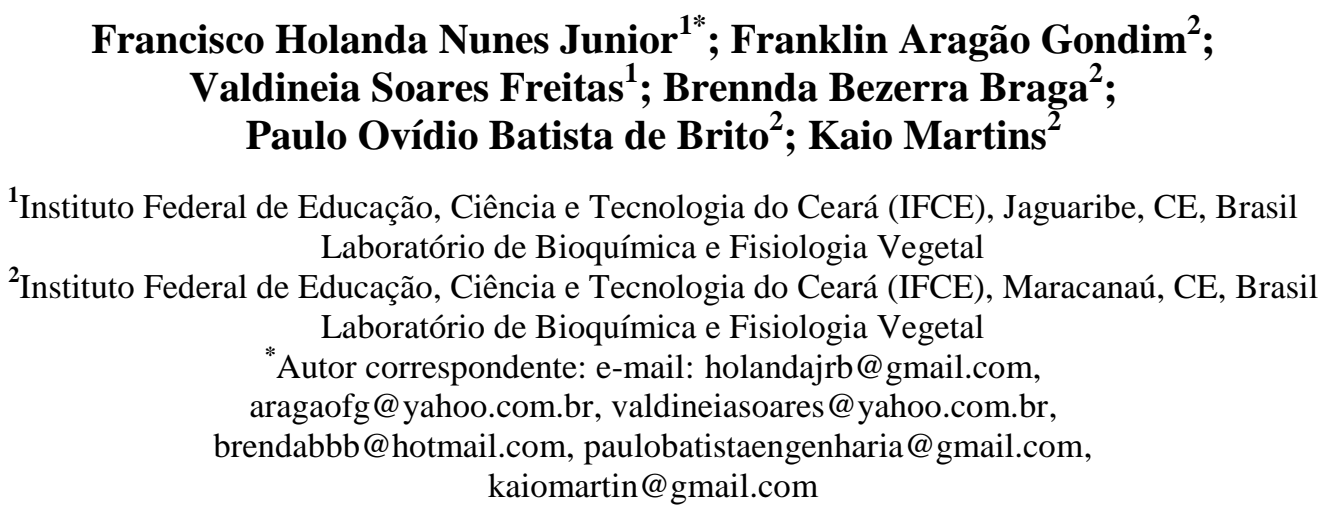

\section{RESUMO}

Em regiões áridas ou semiáridas, a escassez hídrica tem sido um dos principais fatores limitantes da produção agrícola. Diante disso, o presente trabalho objetivou analisar os efeitos da aplicação de percolado de aterro sanitário no crescimento foliar (número de folhas e área foliar) e as atividades das enzimas antioxidativas: superóxido dismutase (SOD), catalase (CAT), peroxidase do ascorbato (APX) e peroxidase do guaiacol (GPX) em folhas e raízes de plântulas de girassol submetidas às condições de estresse hídrico. $O$ delineamento experimental foi o inteiramente casualizado, disposto em arranjo fatorial dois (irrigadas ou não irrigadas) x quatro (areia; areia + adubo orgânico $100 \mathrm{~kg} \mathrm{~N} \mathrm{ha}^{-1}$; areia + percolado de aterro sanitário $100 \mathrm{~kg} \mathrm{~N} \mathrm{ha}^{-1}$; areia + percolado de aterro sanitário $150 \mathrm{~kg} \mathrm{~N}$ ha $^{-1}$ ), com cinco repetições. Em relação aos parâmetros foliares, o tratamento $100 \mathrm{~kg} \mathrm{~N} \mathrm{ha}^{-1}$ suplementado com percolado de aterro sanitário obteve os melhores incrementos no número de folhas e área foliar. Além disso, verificaram-se aumentos nas atividades das enzimas antioxidativas em folhas e raízes de plântulas de girassol suplementadas com percolado de aterro sanitário, sendo provável que as reduções dos efeitos deletérios do estresse hídrico nas variáveis foliares dos tratamentos suplementados com percolado de aterro sanitário tenham ocorrido em virtude das maiores atividades das enzimas antioxidativas, especialmente as da CAT nas folhas e GPX nas raízes.

Palavras-chave: chorume, estresse oxidativo, Helianthus annuus L, seca.

\section{Leaf growth and antioxidative enzyme activities in sunflower seedlings supplemented by sanitary landfill leachate under drought stress}

\section{ABSTRACT}

In arid or semi-arid regions, the limited availability of water resources has been one the main limiting factors in agricultural production. We analyzed the effects of the application of 
sanitary landfill leachate on the growth of leaves (number of leaves and leaf area) and the activities of the antioxidative enzymes superoxide dismutase (SOD), catalase (CAT), ascorbate peroxidase (APX) and guaiacol peroxidase (GPX) in the leaves and roots of sunflower seedling subjected to drought stress. The experimental design was completely randomized in a factorial two (irrigated and non-irrigated) $\mathrm{x}$ four (sand; sand + organic fertilizer $100 \mathrm{~kg} \mathrm{~N} \mathrm{ha}^{-1}$; sand + sanitary landfill leachate $100 \mathrm{~kg} \mathrm{~N} \mathrm{ha}^{-1}$; sand + sanitary landfill leachate $150 \mathrm{~kg} \mathrm{~N} \mathrm{ha}^{-1}$ ) with five replicates. In relation to foliar growth, the treatment $100 \mathrm{~kg} \mathrm{~N} \mathrm{ha}^{-1}$ supplemented by sanitary landfill leachate increased the number of leaves and leaf area. In addition, there were increases in the antioxidative enzymes' activities in leaves and roots of sunflower seedlings supplemented by sanitary landfill leachate. Thus, it is possible that the reductions in harmful effects of drought stress on the leaves' growth in treatments supplemented by sanitary landfill leachate occurred due to increased antioxidative enzymes activities, especially CAT in leaves and GPX in roots.

Keywords: chorume, drought, Helianthus annuus L., oxidative stress.

\section{INTRODUÇÃO}

A seca é um dos principais fatores limitantes da produção agrícola nas regiões áridas e semiáridas. Nesses ambientes, as plantas podem enfrentar situações de déficit hídrico devido à limitada disponibilidade de água no ambiente radicular, ou quando a taxa evapotranspiratória torna-se excessiva (Ghobadi et al., 2013).

De modo geral, as plantas tendem a fechar seus estômatos como resposta inicial ao déficit hídrico, a fim de reduzir a taxa de transpiração. Consequentemente, a taxa fotossintética é reduzida devido à menor disponibilidade de $\mathrm{CO}_{2}$, podendo ocorrer aumento da respiração. A baixa concentração de $\mathrm{CO}_{2}$ na etapa bioquímica da fotossíntese reduz a oxidação de NADPH no ciclo de Calvin-Benson, e, consequentemente, sua disponibilidade sob a forma de $\mathrm{NADP}^{+}$na etapa fotoquímica. Assim, este processo poderá resultar na transferência de elétrons da ferredoxina reduzida no fotossistema $\mathrm{I}$ ao $\mathrm{O}_{2}$, e aumentar a produção de espécies reativas de oxigênio ROS (do inglês Reactive Oxigen Species), com danos ao aparato fotossintético e estresse oxidativo (Pereira et al., 2012; Ghobadi et al., 2013; Cerqueira et al., 2015).

As ROS são produzidas naturalmente através do metabolismo celular de organelas como as mitocôndrias, cloroplastos e peroxissomos (Karuppanapandian et al., 2011), sendo produzidos o oxigênio singleto $\left({ }^{1} \mathrm{O}_{2}\right)$, o radical superóxido $\left({ }^{\circ} \mathrm{O}_{2}{ }^{-}\right)$e hidroxil $\left({ }^{\circ} \mathrm{OH}\right)$ e o peróxido de hidrogênio $\left(\mathrm{H}_{2} \mathrm{O}_{2}\right)$ (Sharma et al., 2012).

Ainda não está totalmente elucidado o papel da produção e controle das concentrações de ROS durante o estresse hídrico em plantas. De maneira geral, os estresses abióticos estão associados à produção de ROS, sendo, em baixas concentrações, necessários como sinalizadores do processo de aclimatação das plantas (Ren et al., 2016). No entanto, quando há um desequilíbrio entre produção e eliminação, desencadeiam-se danos às proteínas e aos ácidos nucleicos, além da peroxidação de lipídios de membrana, podendo levar as células do organismo à morte (Miller et al., 2010).

Diante disso, as plantas desenvolveram mecanismos enzimáticos e não enzimáticos (antioxidantes de baixos pesos moleculares) de defesa, capazes de eliminar os efeitos citotóxicos das ROS. No sistema enzimático, destacam-se: a superóxido dismutase (SOD), a catalase (CAT), a peroxidase do ascorbato (APX), bem como peroxidases não específicas quanto ao doador de elétrons, como a peroxidase do guaiacol (GPX). Estas enzimas atuam conjuntamente na eliminação das ROS (Deuner et al., 2008; Barbosa et al., 2014).

A enzima SOD atua na conversão do radical superóxido $\left({ }^{\circ} \mathrm{O}_{2}{ }^{-}\right)$a peróxido de hidrogênio 
$\left(\mathrm{H}_{2} \mathrm{O}_{2}\right)$ e oxigênio $\left(\mathrm{O}_{2}\right) . \mathrm{O} \mathrm{H}_{2} \mathrm{O}_{2}$ por sua vez, devido à sua toxicidade, é dismutado em $\mathrm{H}_{2} \mathrm{O}$ e $\mathrm{O}_{2}$ pelas enzimas CAT, APX e GPX, a fim de diminuir os efeitos citotóxicos no vegetal (Shehab et al., 2010).

No nordeste brasileiro, em virtude dos grandes períodos de estiagem, a água é o principal fator limitante para a produção agrícola, seguido pela baixa fertilidade de seus solos (Xavier et al., 2014). O uso de efluentes pode se tornar uma opção para reduzir o uso de águas com qualidades superiores na irrigação e gastos com fertilizantes. Adicionalmente, ressaltam-se como vantagens: o controle da poluição ambiental, a reciclagem de nutrientes e o aumento da produção agrícola (Silva et al., 2011).

Proveniente da decomposição dos resíduos sólidos dispostos nos aterros sanitários, o percolado é um efluente de variada composição físico-química, destacando-se a presença de matéria orgânica, macro e micronutrientes inorgânicos que possibilitam sua utilização como fonte de nutrientes e água no cultivo de plantas (Canto et al., 2013; Coelho et al., 2015).

Originário da América do Norte, o girassol (Helianthus annuus L.) é uma planta tolerante à seca e à salinidade (NSA, 2010). Seu cultivo tem sido feito principalmente para a extração de óleo, estando a cultura entre as quatro principais produtoras do mundo (FAO, 2013). Adicionalmente, a planta vem sendo considerada como uma das espécies de maior potencial para produção de biocombustíveis, sendo também bastante empregada em sistemas de sucessão ou rotação de culturas, devido à tolerância a diferentes tipos de climas e solos (Glovatski e Raiher, 2013; Gomes et al., 2015).

Apesar de o girassol ser considerado uma espécie com boa capacidade de aclimatação às diferentes condições de clima e solo, são escassos na literatura informações sobre os efeitos da suplementação com percolado de aterro sanitário no crescimento foliar e nas atividades das enzimas antioxidativas sob condições de estresse hídrico.

Diante do exposto, o presente trabalho objetivou analisar os efeitos da aplicação de percolado de aterro sanitário no crescimento foliar (número de folhas e área foliar) e nas atividades das enzimas antioxidativas em plântulas de girassol submetidas ao estresse hídrico.

\section{MATERIAL E MÉTODOS}

\subsection{Percolado de aterro sanitário utilizado no experimento}

O percolado utilizado no experimento foi coletado no mês de agosto de 2015, no Aterro Sanitário Metropolitano Oeste da Caucaia (ASMOC) na $3^{\text {a }}$ lagoa de estabilização (aeróbica facultativa) próxima ao vertedouro, localizado no município de Caucaia, Ceará, Brasil. A coleta do efluente obedeceu às normas de estocagem, manutenção e transporte, de acordo com os parâmetros físico-químicos analisados (Tabela 1).

Tabela 1. Caracterização físico-química do percolado de aterro sanitário utilizado no experimento.

\begin{tabular}{|c|c|c|c|c|c|c|c|c|c|c|c|}
\hline \multicolumn{12}{|c|}{$\mathrm{mg} \mathrm{L}^{-1}$} \\
\hline $\mathrm{N}-\mathrm{t}$ & $\mathrm{NH}_{4}$ & $\mathrm{NO}_{3-}$ & $\mathrm{NO}_{2-}$ & P-t & $\mathrm{Fe}^{+2}$ & $\mathrm{Zn}$ & $\mathrm{Mn}$ & $\mathrm{Cu}$ & $\mathrm{P}_{2} \mathrm{O}_{5}$ & $\mathrm{C} / \mathrm{N}$ & C.O.T. \\
\hline 504 & 323 & 153 & 19 & 7,9 & 16,1 & 22,3 & 24,5 & 1,5 & 18,1 & 1,39 & 660 \\
\hline \multicolumn{8}{|c|}{$\mathrm{mg} \mathrm{L}^{-1}$} & \multicolumn{4}{|c|}{-- dS m ${ }^{-1}--$} \\
\hline $\mathrm{K}_{2} \mathrm{O}$ & $\mathrm{K}^{+}$ & $\mathrm{Na}^{+}$ & $\mathrm{Ca}^{2+}$ & $\mathrm{Mg}^{2+}$ & $\mathrm{Cl}^{-}$ & $\mathrm{CO}_{3}^{-2}$ & $\mathrm{HCO}_{3}^{-}$ & & $\mathrm{pH}$ & C.E. & RAS \\
\hline 2.196 & 1.800 & 234,6 & 54 & 58,5 & $2.428,5$ & 96 & 231,8 & & 7,8 & 7,6 & 5,37 \\
\hline
\end{tabular}

N-t: nitrogênio total; P-t: fósforo total; C/N: razão carbono nitrogênio; C.O.T.: carbono orgânico total; C.E.: condutividade elétrica; RAS: razão de adsorção de sódio. 


\subsection{Condições experimentais, tratamentos e coleta das plântulas}

O experimento foi conduzido em casa de vegetação localizada na cidade de Maracanaú, Ceará, Brasil, no período de Setembro a Outubro de 2015. Os valores médios de temperatura e umidade relativa do ar, foram, respectivamente, $32,1^{\circ} \mathrm{C}$ e $52 \%$.

As sementes de girassol (Helianthus annuus L.) do cultivar BRS 323 foram cedidas pela Embrapa Produtos e Mercados - Escritório Dourados, Mato Grosso do Sul, Brasil. Após seleção e desinfestação com solução de hipoclorito de sódio a $0,7 \%$, as sementes foram semeadas em vasos de plástico de $5 \mathrm{~L}$ preenchidos com: 1) areia de granulometria fina (NBR 6502); 2) areia + adubo/fertilizante orgânico comercial misto (11,8\% de nitrogênio - N) aplicado proporcionalmente ao correspondente a $100 \mathrm{~kg} \mathrm{~N} \mathrm{ha}^{-1} /$ vaso; 3) areia + percolado de aterro sanitário aplicado proporcionalmente ao correspondente a $100 \mathrm{~kg} \mathrm{~N} \mathrm{ha}^{-1} /$ vaso; 4) areia + percolado de aterro sanitário aplicado proporcionalmente ao correspondente a $150 \mathrm{~kg} \mathrm{~N} \mathrm{ha}^{-1} /$ vaso. Durante o experimento, foram realizadas regas diárias, mantendo-se a umidade próxima a $70 \%$ da capacidade de campo do substrato.

Decorridos 16 dias após a semeadura (DAS), metade de cada grupo de plantas de cada tratamento descrito acima, foi submetido à suspensão da rega. Foram realizadas 2 coletas: $1^{\mathrm{a}}$ ) aos 21 dias após a semeadura (5 dias sob estresse hídrico) e $2^{\mathrm{a}}$ ) aos 23 dias (7 dias sob estresse hídrico). Durante as coletas, determinaram-se: o número de folhas e a área foliar (usando-se o medidor de área foliar ADC, modelo: AM350).

$\mathrm{O}$ delineamento experimental foi inteiramente casualizado disposto em arranjo fatorial dois (irrigadas ou não irrigadas) x quatro (areia; areia + adubo orgânico $100 \mathrm{~kg} \mathrm{~N} \mathrm{ha}^{-1}$; areia + percolado de aterro $100 \mathrm{~kg} \mathrm{~N} \mathrm{ha}^{-1}$; areia + percolado de aterro $150 \mathrm{~kg} \mathrm{~N} \mathrm{ha}^{-1}$ ), com cinco repetições, cada uma constituída por um vaso com duas plantas. Os dados de cada período de coleta foram, independentemente, submetidos à análise de variância (ANOVA) e as médias foram comparadas pelo teste de Tukey $(P \leq 0,05)$ através do programa Sigma Plot 11.0.

\subsection{Preparação dos extratos enzimáticos e determinações das atividades das enzimas antioxidativas}

Para as determinações das atividades das enzimas antioxidativas foram preparados extratos de folhas e raízes frescas obtidas a partir da maceração, em almofariz, de $1 \mathrm{~g}$ de matéria fresca em nitrogênio líquido para obtenção do pó. Em seguida, adicionaram-se 4,0 $\mathrm{mL}$ de tampão fosfato de potássio a $100 \mathrm{mM}, \mathrm{pH} 7,0$, contendo EDTA a $0,1 \mathrm{mM}$. O macerado foi filtrado em tecido de náilon de malha fina e centrifugado a $12.000 \mathrm{x} \mathrm{g}$ durante 15 min.

Foram determinadas as atividades das enzimas CAT, GPX, APX e SOD. A atividade da CAT foi determinada de acordo com Havir e McHale (1987), pelo decréscimo na absorbância em $240 \mathrm{~nm}$, devido ao consumo de $\mathrm{H}_{2} \mathrm{O}_{2}$; a da GPX pelo método de Kar e Mishra (1976), sendo a reação acompanhada pelo incremento da absorbância em $470 \mathrm{~nm}$, devido à formação do tetraguaiacol; a da APX pelo método de Nakano e Asada (1981), sendo a oxidação do ascorbato medida pelo decréscimo na absorbância em $290 \mathrm{~nm}$, e a da SOD pelo método de Beauchamp e Fridovich (1971), sendo a reação medida através do aumento da absorbância em $560 \mathrm{~nm}$, devido à produção de formazana azul, resultante da fotorredução do p-Nitrobluetetrazolium (NBT). As atividades das enzimas CAT, APX e GPX foram expressas em $\mu$ mol $\mathrm{H}_{2} \mathrm{O}_{2} \mathrm{~min}^{-1} \mathrm{~g}^{-1} \mathrm{MF}$, e a da SOD em UA g ${ }^{-1} \mathrm{MF}$, onde MF representa matéria fresca e sendo uma UA (unidade de atividade enzimática) definida como sendo a quantidade de enzima necessária para causar $50 \%$ de inibição da fotorredução do NBT. Cada extrato foi dosado em duplicata. 


\section{RESULTADOS E DISCUSSÃO}

\subsection{Número de folhas e área foliar}

A análise de variância demonstrou que houve interações entre os fatores: diferentes suplementações de $\mathrm{N}$ com percolado no substrato, e irrigação (plantas irrigadas ou não irrigadas) utilizados no cultivo de maneira significativa a $1 \%$ de probabilidade $(P \leq 0,001)$ nas variáveis: número de folhas (NF) e área foliar (AF) (Tabela 2).

Tabela 2. Resumos das análises de variância do número de folhas (NF) e área foliar (AF) de plantas de girassol em diferentes suplementações de $\mathrm{N}$ com percolado nos substratos (areia; areia + adubo/fertilizante orgânico comercial misto a $100 \mathrm{~kg} \mathrm{~N} \mathrm{ha}^{-1}$; areia + percolado de aterro sanitário a $100 \mathrm{~kg} \mathrm{~N}^{-1}$; areia + percolado de aterro sanitário a $150 \mathrm{~kg} \mathrm{~N} \mathrm{ha}^{-1}$ ) sob condições controle e estresse hídrico aos 5 e 7 dias após a suspensão da irrigação.

\begin{tabular}{|c|c|c|c|c|c|}
\hline \multirow[b]{3}{*}{ Fonte de Variação } & \multirow[b]{3}{*}{ GL } & \multicolumn{4}{|c|}{ Quadrado Médio } \\
\hline & & \multicolumn{2}{|c|}{ NF } & \multicolumn{2}{|c|}{$\mathrm{AF}$} \\
\hline & & 05 dias & 07 dias & 05 dias & 07 dias \\
\hline Suplementação (S) & 3 & $13,36^{*}$ & $18,60^{*}$ & $5970,5^{*}$ & $7468,6^{*}$ \\
\hline Irrigação (I) & 1 & $19,60^{*}$ & $16,90^{*}$ & $572,2^{*}$ & $7942,5^{*}$ \\
\hline$S \times I$ & 3 & $1,40^{*}$ & $5,90^{*}$ & $124,7^{*}$ & $2138,6^{*}$ \\
\hline Erro & 32 & 0,16 & 0,06 & 5,83 & 10,12 \\
\hline Total Corrigido & 39 & - & - & - & - \\
\hline CV (\%) & - & 6,55 & 3,37 & 5,65 & 6,03 \\
\hline
\end{tabular}

$\mathbf{N F}=$ número de folhas;

$\mathbf{A F}=$ área foliar; $\mathrm{e}$

$* P \leq 0,001$.

De maneira geral, o estresse hídrico promoveu reduções no número de folhas e na área foliar em todos os tratamentos (Figuras 1A e 1B), com diferenças significativas em relação ao controle. Adicionalmente, na condição de estresse hídrico, verificou-se que o tratamento areia + percolado de aterro sanitário a $100 \mathrm{~kg} \mathrm{~N} \mathrm{ha}^{-1}$ apresentou os maiores valores de NF e $\mathrm{AF}$, com diferenças significativas em relação aos demais tratamentos, nos dois períodos de análise.

As reduções observadas no presente trabalho são semelhantes às encontradas por outros autores, tanto com plantas de girassol (Manivannan et al., 2007; Nobre et al., 2011; Dutra et al., 2012), como com outras espécies (Zhang et al., 2004; Wullschleger et al., 2005; Santos et al., 2012) sob condições de estresse hídrico ou salino.

O crescimento vegetal depende da divisão e expansão de suas células, sendo esta última condicionada à pressão de turgência, processo afetado pela baixa disponibilidade de água no solo ou pelo excesso de transpiração (Santos et al., 2014). De maneira adicional, Jaleel et al. (2009) afirmam que, sob condições de estresse hídrico, as plantas reduzem a emissão de novas folhas e a área foliar como mecanismo para evitar a perda de água por transpiração. Porém, isso pode ocasionar a diminuição da capacidade fotossintética do vegetal, bem como a formação de ROS (Silva et al., 2011).

Em relação aos efeitos das ROS sobre o NF e AF, Deuner et al. (2011) afirmam que em condições de estresses abióticos, é necessária a rápida eliminação das ROS pelas enzimas 
antioxidativas para se evitar a diminuição do crescimento e da produtividade do vegetal.

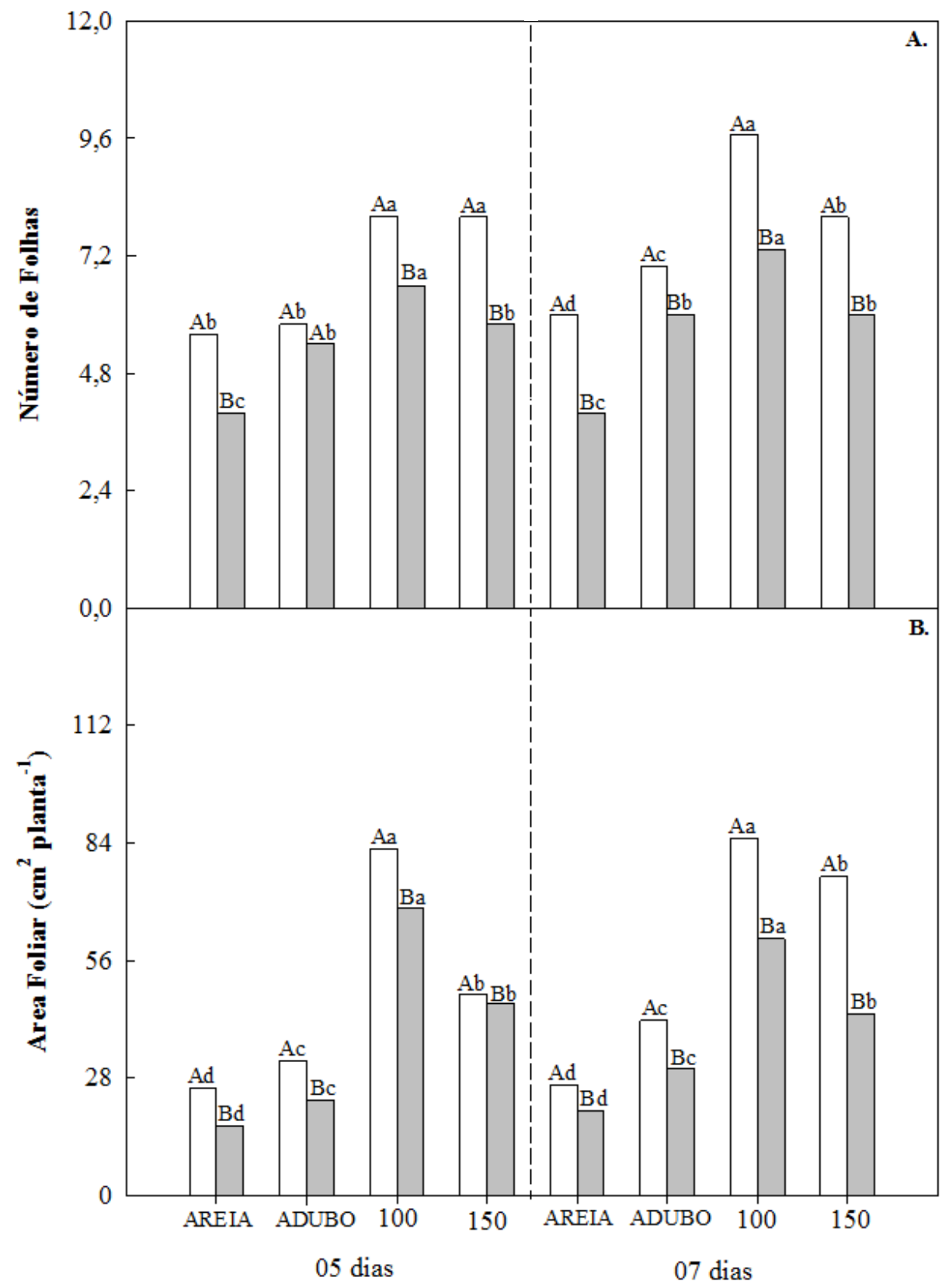

Figura 1. Número de folhas (A) e área foliar (B) de plantas de girassol aos 5 $\left(1^{\mathrm{a}}\right.$ coleta) e 7 dias ( $2^{\mathrm{a}}$ coleta) após a suspensão da irrigação (que ocorreu aos 16 dias após a semeadura) crescendo sob condições controle (barras brancas) ou de estresse hídrico (barras cinzas). Diferentes letras maiúsculas indicam diferenças significativas ao tipo de irrigação (controle e estresse), enquanto diferentes letras minúsculas indicam diferenças significativas em relação às diferentes suplementações de $\mathrm{N}$ com percolado nos substratos (areia; areia + adubo orgânico $100 \mathrm{~kg} \mathrm{~N} \mathrm{ha}^{-1}$; areia + percolado de aterro $100 \mathrm{~kg} \mathrm{~N}$ ha $^{-1}$; areia + percolado de aterro $\left.150 \mathrm{~kg} \mathrm{~N} \mathrm{ha}^{-1}\right)$, de acordo com o teste de Tukey $(P \leq$ $0,05)$. As análises estatísticas foram realizadas independentemente em cada coleta.

\subsection{Atividade enzimática nas folhas}

A análise de variância demonstrou que houve interações entre os fatores: diferentes 
suplementações de $\mathrm{N}$ com percolado no substrato, e irrigação (plantas irrigadas ou não irrigadas) utilizados no cultivo ( $\mathrm{T} \times \mathrm{I})$ de maneira significativa a $1 \%$ de probabilidade $(P \leq 0,001)$ nos parâmetros de atividade das enzimas CAT, APX, GPX e SOD em folhas de plantas de girassol aos 5 dias após suspensão da irrigação (Tabela 3). No entanto, aos 7 dias após suspensão da irrigação, a interação ( $\mathrm{T}$ x I) mostrou-se não significativa para a CAT e significativa a $5 \%$ de probabilidade $(P \leq 0,005)$ para a SOD.

Tabela 3. Resumos das análises de variância da atividade das enzimas, catalase (CAT), peroxidase do ascorbato (APX), peroxidase do guaiacol (GPX) e superóxido dismutase (SOD) em folhas de plantas de girassol em diferentes suplementações de $\mathrm{N}$ com percolado no substrato (areia; areia + adubo/fertilizante orgânico comercial misto a $100 \mathrm{~kg} \mathrm{~N} \mathrm{ha}^{-1}$; areia + percolado de aterro sanitário a $100 \mathrm{~kg} \mathrm{~N} \mathrm{ha}^{-1}$; areia + percolado de aterro sanitário a $150 \mathrm{~kg} \mathrm{~N} \mathrm{ha}^{-1}$ ) sob condições controle e estresse hídrico aos 5 e 7 dias após a suspensão da irrigação.

\begin{tabular}{|c|c|c|c|c|c|c|c|c|c|}
\hline \multirow[b]{3}{*}{ Fonte de Variação } & \multirow[b]{3}{*}{ GL } & \multicolumn{8}{|c|}{ Quadrado Médio } \\
\hline & & \multicolumn{2}{|c|}{ CAT } & \multicolumn{2}{|c|}{ APX } & \multicolumn{2}{|c|}{ GPX } & \multicolumn{2}{|c|}{ SOD } \\
\hline & & 05 dias & 07 dias & 05 dias & 07 dias & 05 dias & 07 dias & 05 dias & 07 dias \\
\hline Suplementação (S) & 3 & $1944,1^{*}$ & $3867,6^{*}$ & $0,048^{*}$ & $0,060^{*}$ & $0,24^{*}$ & $0,33^{*}$ & $181,8^{*}$ & $33,4^{*}$ \\
\hline Irrigação (I) & 1 & $185,3^{*}$ & $40,8^{\mathrm{ns}}$ & $0,155^{*}$ & $0,087^{*}$ & $1,12^{*}$ & $1,01^{*}$ & $10,9^{*}$ & $45,3^{*}$ \\
\hline S x I & 3 & $51,4^{*}$ & $2,45^{\mathrm{ns}}$ & $0,039^{*}$ & $0,004^{\mathrm{ns}}$ & $0,13^{*}$ & $0,05^{*}$ & $3,8^{*}$ & $4,2^{* *}$ \\
\hline Erro & 32 & 6,1 & $9,53^{*}$ & 0,0019 & 0,0009 & 0,014 & 0,004 & $0,27^{*}$ & 0,80 \\
\hline Total Corrigido & 39 & - & - & - & - & - & - & - & - \\
\hline CV (\%) & - & 12,1 & 13,3 & 15,07 & 10,4 & 5,44 & 3,23 & 0,69 & 1,21 \\
\hline
\end{tabular}

Na Figura 2 são apresentadas as atividade das enzimas SOD, CAT, APX e GPX em folhas de plântulas de girassol aos 5 e 7 dias após suspensão da irrigação.

As atividades da SOD nas folhas (Figura 2A) mostraram-se maiores aos 5 e 7 dias nas plântulas suplementadas com percolado de aterro sanitário (100 e $150 \mathrm{~kg} \mathrm{~N}^{-1}$ ) e que tiveram a irrigação suspensa. De maneira adicional, as plântulas suplementadas com percolado de aterro sanitário não diferiram entre si na condição de suspensão da irrigação, e mostraram, em média, atividades superiores aos dos tratamentos areia e adubo em $4 \%$ e $7 \%$, respectivamente.

As atividades da CAT nas folhas das plântulas de girassol (Figura 2B) foram mais elevadas nos tratamentos suplementados com percolado de aterro nos dois períodos de coleta (aos 5 e 7 dias após suspensão da irrigação). De maneira adicional, em uma mesma suplementação de $\mathrm{N}$, no segundo período de coleta, não foram verificadas diferenças significativas nas atividades enzimáticas das plantas controle (irrigadas) e estresse (não irrigadas) em nenhum dos tratamentos. 


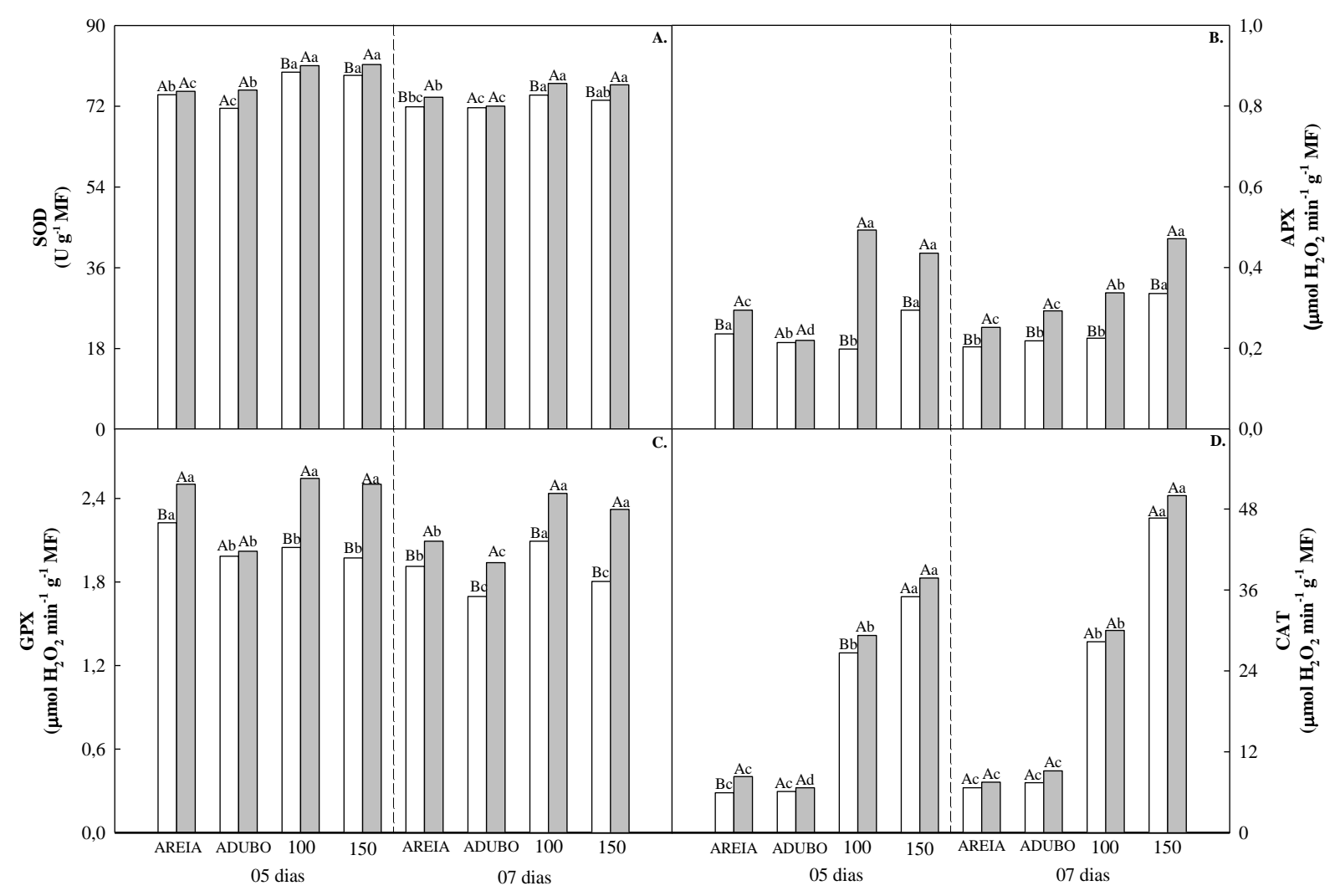

Figura 2. Atividade das enzimas superóxido dismutase - SOD (A), peroxidase do ascorbato APX (B), peroxidase do guaiacol - GPX (C) e catalase - CAT (D) em folhas de plantas de girassol aos 05 ( $1^{\mathrm{a}}$ coleta) e 07 dias ( $2^{\mathrm{a}}$ coleta) após a suspensão da irrigação (que ocorreu aos 16 dias após a semeadura) crescendo sob condições controle (barras brancas) ou de estresse hídrico (barras cinzas). Detalhes adicionais na legenda da Figura 1.

Aos 5 e 7 dias de suspensão da irrigação, sob condições de estresse, a atividade da APX nas folhas (Figura 2C), mostrou-se mais elevada nos tratamentos 100 e $150 \mathrm{~kg} \mathrm{~N} \mathrm{ha}^{-1}$. Adicionalmente, no segundo período de coleta, o tratamento suplementado com percolado a $150 \mathrm{~kg} \mathrm{~N} \mathrm{ha}^{-1}$ apresentou diferenças em relação aos tratamentos areia e adubo de 87 e $61 \%$, respectivamente.

Já para a atividade da GPX nas folhas das plantas de girassol (Figuras 2D), após 5 dias de suspensão da irrigação, sob condições de estresse, as maiores atividades enzimáticas foram observadas nos tratamentos areia e percolado de aterro sanitário (100 e $150 \mathrm{~kg} \mathrm{~N}^{-1}$ ), não havendo diferenças estatísticas entre si. Entretanto, aos 7 dias de suspensão da irrigação, os tratamento com percolado apresentaram atividades superiores aos tratamentos areia e adubo, de 16 e $26 \%$ respectivamente.

\subsection{Atividade enzimática nas raízes}

A análise de variância demonstrou que houve interações entre os fatores: diferentes suplementações de $\mathrm{N}$ com percolado no substrato, e irrigação (plantas irrigadas ou não irrigadas), utilizados no cultivo ( $\mathrm{T}$ x I) de maneira significativa a $1 \%$ de probabilidade $(P \leq 0,001)$ nas atividades de APX, GPX e SOD em raízes de plantas de girassol aos 7 dias após suspensão da irrigação (Tabela 4). No entanto, aos 5 dias após a suspensão da irrigação, a interação ( T x I) mostrou-se não significativa para a enzima APX. 
Tabela 4. Resumos das análises de variância da atividade das enzimas, peroxidase do ascorbato (APX), peroxidase do guaiacol (GPX) e superóxido dismutase (SOD) em raízes de plantas de girassol em diferentes suplementações de $\mathrm{N}$ com percolado no substrato (areia; areia + adubo/fertilizante orgânico comercial misto a $100 \mathrm{~kg} \mathrm{~N}^{-1}$; areia + percolado de aterro sanitário a $100 \mathrm{~kg} \mathrm{~N} \mathrm{ha}^{-1}$; areia + percolado de aterro sanitário a $150 \mathrm{~kg} \mathrm{~N} \mathrm{ha}^{-1}$ ) sob condições controle e estresse hídrico aos 5 e 7 dias após a suspensão da irrigação.

\begin{tabular}{|c|c|c|c|c|c|c|c|}
\hline \multirow[b]{3}{*}{ Fonte de Variação } & \multirow[b]{3}{*}{ GL } & \multicolumn{6}{|c|}{ Quadrado Médio } \\
\hline & & \multicolumn{2}{|c|}{ APX } & \multicolumn{2}{|c|}{ GPX } & \multicolumn{2}{|c|}{ SOD } \\
\hline & & 05 dias & 07 dias & 05 dias & 07 dias & 05 dias & 07 dias \\
\hline Suplementação (S) & 3 & $0,020^{*}$ & $0,064^{*}$ & $2,97^{*}$ & $1,33^{*}$ & $71,1^{*}$ & $23,74^{*}$ \\
\hline Irrigação (I) & 1 & $0,00009^{\mathrm{ns}}$ & $0,193^{*}$ & $2,03^{*}$ & $14,06^{*}$ & $367,2^{*}$ & $47,74^{*}$ \\
\hline$S \times I$ & 3 & $0,002^{\mathrm{ns}}$ & $0,040^{*}$ & $0,36^{*}$ & $3,20^{*}$ & $83,1^{*}$ & $26,18^{*}$ \\
\hline Erro & 32 & 0,0011 & 0,0011 & 0,011 & 0,008 & 3,60 & 2,06 \\
\hline Total Corrigido & 39 & - & - & - & - & - & - \\
\hline $\mathrm{CV}(\%)$ & - & 11,2 & 12,1 & 6,5 & 5,7 & 3,09 & 2,3 \\
\hline
\end{tabular}

Na Figura 3, são apresentadas as atividade das enzimas SOD, APX e GPX em raízes de plantas de girassol aos 5 e 7 dias após a suspensão da irrigação. $\mathrm{Na}$ atividade da SOD nas raízes (Figura 3A), aos 5 e 7 dias após suspensão da irrigação, foram verificadas diferenças entre o controle e o estresse apenas nos tratamentos que receberam percolado. Adicionalmente, aos 7 dias, na condição de estresse, verificou-se uma maior atividade enzimática no tratamento suplementado com percolado a $100 \mathrm{~kg} \mathrm{~N} \mathrm{ha}^{-1}$, com diferenças de $5 \mathrm{e}$ $11 \%$ em relação aos tratamentos areia e adubo, respectivamente.

No presente trabalho, não foram verificadas atividades da enzima CAT nas raízes das plântulas de girassol.

Aos 5 dias após suspensão da irrigação, nas raízes das plântulas de girassol, não houve diferenças significativas entre os tratamentos controle e estresse na atividade da APX (Figura 3B). No entanto, aos 7 dias após suspensão da irrigação, a atividade da APX mostrou-se mais elevada nas plantas submetidas a estresse quando comparadas com seus respectivos controles. De maneira adicional, sob condições de estresse, o tratamento $100 \mathrm{~kg} \mathrm{~N}$ (areia + percolado de aterro sanitário) apresentou a maior atividade da APX, com diferenças de 64 e $158 \%$ em relação aos tratamentos areia e adubo, respectivamente.

Para a atividade da GPX nas raízes (Figura 3C), de modo geral os tratamentos submetidos a estresse hídrico e suplementados com percolado apresentaram maiores atividades enzimáticas. Entretanto, nos dois períodos de análise, o tratamento $150 \mathrm{~kg} \mathrm{~N} \mathrm{ha}{ }^{-1}$ apresentou os maiores valores de atividade da GPX, sendo as diferenças para os tratamentos areia de 138 e $112 \%$, e adubo de 94 e $120 \%$, aos 5 e 7 dias após a suspensão da irrigação, respectivamente. 


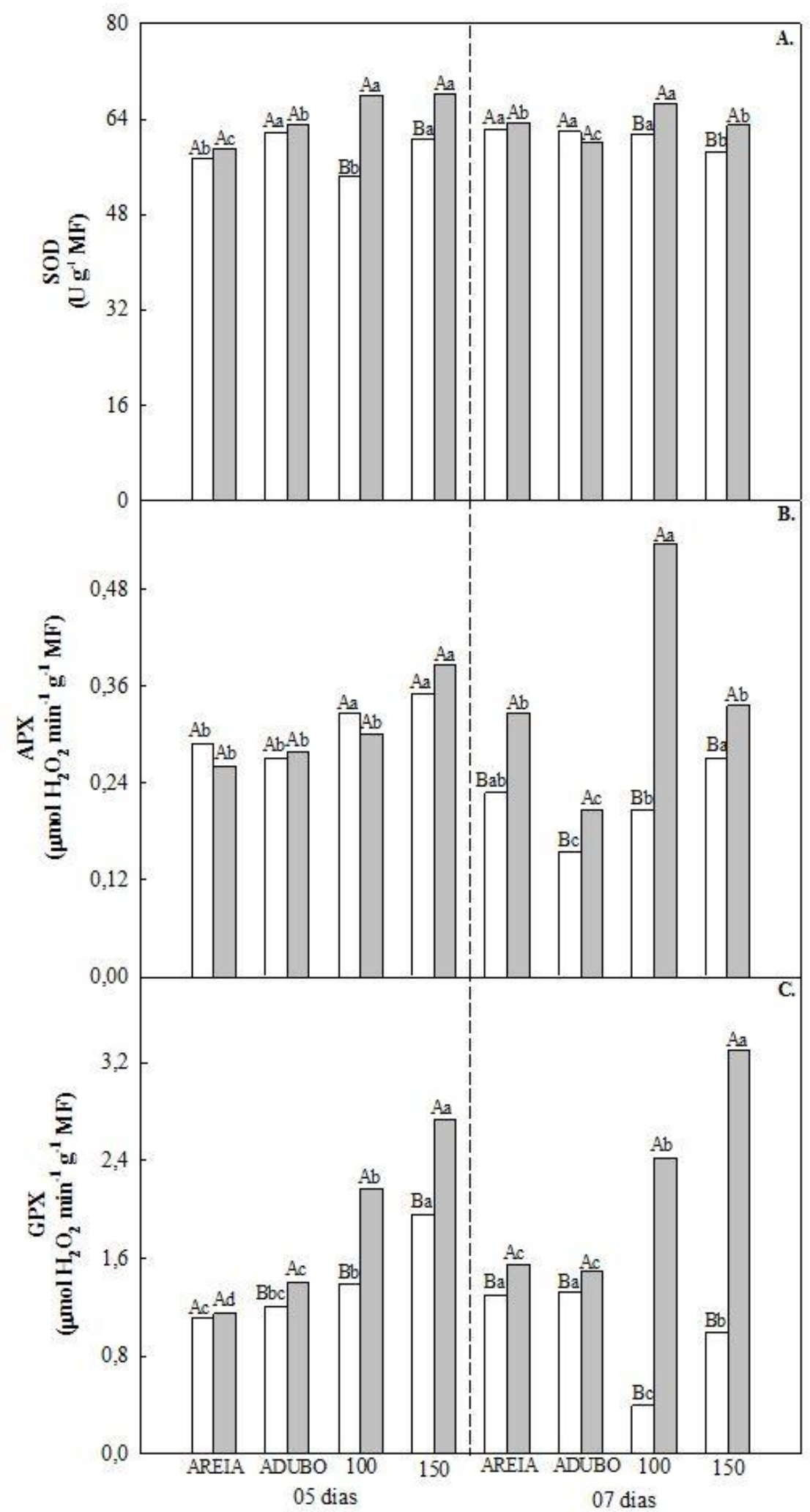

Figura 3. Atividade das enzimas superóxido dismutase - SOD (A), peroxidase do ascorbato - APX (B), peroxidase do guaiacol - GPX (C) e catalase - CAT (D) em folhas de plantas de girassol aos 05 ( $1^{\text {a }}$ coleta) e 07 dias ( $2^{\mathrm{a}}$ coleta) depois de submetidas a estresse hídrico crescendo sob condições controle (barras brancas) ou estresse hídrico (barras cinzas). Detalhes adicionais na legenda da Figura 1. 
De modo geral, na condição de estresse hídrico, a aplicação de percolado de aterro sanitário promoveu aumentos nas atividades enzimáticas de folhas e raízes em relação aos demais tratamentos. Resultados similares são descritos em estudos com girassol (Manivannan et al., 2007; Carneiro et al., 2011) e outras espécies (Azevedo Neto et al., 2010; Carneiro et al.; 2015) sob condições de estresse hídrico e salino.

De maneira adicional, há um consenso entre diversos autores sobre os aumentos nas atividades das enzimas antioxidativas em plantas e seus benefícios no controle ao aumento das ROS e promoção da aclimatação das plantas aos estresses abióticos (Willadino et al., 2011; Gondim et al., 2012; Kanungo e Joshi, 2014; Jadoski et al.; 2015).

Verificou-se que nas folhas das plântulas de girassol suplementadas com percolado, a maior atividade da SOD nas condições de estresse promoveu maiores atividades da CAT e das peroxidases (APX e GPX) em relação aos demais tratamentos. Isto pode ser explicado pelo fato de a SOD ser a primeira enzima envolvida no sistema de defesa das plantas, atuando na dismutação do radical superóxido $\left(\mathrm{O}_{2}{ }^{-}\right)$em peróxido de hidrogênio $\left(\mathrm{H}_{2} \mathrm{O}_{2}\right)$, substrato de catálise das peroxidases (Gill e Tuteja, 2010).

No entanto, dentre as enzimas avaliadas nas folhas, a suplementação com percolado de aterro sanitário promoveu aumentos substanciais na atividade da CAT em relação à APX e à GPX. Aos 7 dias após suspensão da irrigação, na condição de estresse hídrico, verificou-se atividades na ordem de $50 \mu \mathrm{mol} \mathrm{H}_{2} \mathrm{O}_{2} \mathrm{~min}^{-1} \mathrm{~g}^{-1} \mathrm{MF}$ para a CAT, o que comprova ter havido uma maior eliminação de peróxido de hidrogênio nas plântulas dos respectivos tratamentos.

As inferências acima podem ser feitas em virtude da enzima CAT ser a principal enzima a catalisar a eliminação do $\mathrm{H}_{2} \mathrm{O}_{2}$ (Scandalios, 2005; Jaleel et al., 2009). Além disso, semelhantemente, ao presente trabalho, Akcay et al. (2010), analisando a atividade da CAT em Arachis hypogaea L., também verificaram aumentos acentuados da enzima em condições de estresse hídrico. Adicionalmente, os autores afirmaram que a CAT é uma das enzimas mais eficazes na defesa contra processos oxidativos. Assim, elevadas atividades em Arachis hypogaea L. sob condições de estresse representariam uma melhor capacidade de aclimatação da espécie.

De maneira adicional, Carneiro et al. (2015), avaliando os efeitos de diferentes fontes de nitrogênio no metabolismo antioxidativo em plantas de seringueira, verificaram que os tratamentos que receberam maiores concentrações de $\mathrm{N}$ apresentaram maiores atividades de CAT. Dessa forma, é provável que os aumentos na atividade da CAT no presente trabalho também esteja relacionado ao fornecimento de $\mathrm{N}$ através do percolado.

Em relação às raízes, apesar de não terem sido observadas atividades da CAT, verificouse maiores atividades da SOD e das peroxidases (APX e GPX) nas plântulas suplementadas com percolado de aterro e submetidas a estresse hídrico. Sendo mais elevada a atividade da GPX no tratamento $150 \mathrm{~kg} \mathrm{~N} \mathrm{ha}^{-1}$, nos dois períodos de coleta.

A APX e a GPX são enzimas que necessitam de agentes redutores para a eliminação do $\mathrm{H}_{2} \mathrm{O}_{2}$, sendo, portanto, responsáveis pela regulação fina da concentração de $\mathrm{H}_{2} \mathrm{O}_{2}$ em função da alta afinidade com esta ROS (Ahmad et al., 2010; Silveira et al., 2010; Pereira et al., 2012).

De maneira similar aos resultados verificadas no presente trabalho, Chai et al. (2010), constataram aumentos na atividade da GPX em raízes de plantas de sorgo submetidas a estresse salino. Adicionalmente, Aumonde et al. (2013) identificaram, em raízes de plantas de arroz submetidas a diferentes intensidades de luz, as enzimas APX e GPX como sendo as principais responsáveis pela eliminação do $\mathrm{H}_{2} \mathrm{O}_{2}$.

Perante o exposto, são positivos os aumentos de atividades antioxidativas observados nas raízes e folhas das plântulas suplementadas com percolado, em particular as da CAT nas folhas. Deste modo, é provável que os aumentos nas atividades das enzimas antioxidativas teriam contribuído para minimizar os efeitos deletérios do estresse hídrico nas variáveis de crescimento analisadas (número de folhas e área foliar). 


\section{CONCLUSÕES}

- A aplicação de percolado de aterro sanitário a 100 e $150 \mathrm{~kg} \mathrm{~N}^{-1}$ promoveu os incrementos nas variáveis número de folhas e área foliar, em comparação aos tratamentos areia e adubo, tanto para as condições de controle (plantas irrigadas) como de estresse hídrico (plantas não irrigadas).

- O estresse hídrico promoveu redução no número de folhas e área foliar. No entanto, no tratamento $100 \mathrm{~kg} \mathrm{~N} \mathrm{ha}^{-1}$ suplementado com percolado de aterro sanitário, os efeitos deletérios do estresse hídrico foram minimizados.

- A suplementação com percolado de aterro promoveu aumentos significativos nas atividades das enzimas antioxidativas em folhas e raízes de plântulas de girassol.

\section{REFERÊNCIAS}

AKCAY, U. C.; ERCAN, O.; KAVAS, M.; YILDIZ, L.; YLMAZ, C.; OKTEM, H. A.; YUCEL, M. Drought-induced oxidative damage aond antioxidant responses in peanut (Arachis hygaeae L.) seedling. Plant Growth Regulation, v. 61, p. 21-28, 2010. http://dx.doi.org/10.1007/s10725-010-9445-1

AHMAD, P.; JALEEL, C. A.; SALEM, M. A.; NABI, G.; SHARMA, S. Roles of enzymatic and nonenzymatic antioxidants in plants during abiotic stress. Critical Reviews in Biotechnology, Boca Raton, v. 30, p. 161-175, 2010. http://dx.doi.org/ 10.3109/07388550903524243

AUMONDE, T. Z.; PEDÓ, T.; JUNIOR BORELLA; AMARANTE, L.; VILLELA, F. A. Seed vigor, antioxidant metabolism and initial growth characteristics of red rice seedlings under different light intensities. Acta Botanica Brasilica, v. 27, p. 311-317, 2013. http://dx.doi.org/10.1590/S0102-33062013000200007

AZEVEDO NETO, A. D.; NOGUEIRA, R. J. M. C.; MELO FILHO, P. A.; SANTOS, R. C. Physiological and biochemical responses of peanut genotypes to water déficit. Journal of Plant Interactions, v. 5, p. 1-10, 2010. http://dx.doi.org/10.1080/ 17429140902999243

BARBOSA, M. R.; SILVA, M. M. de A.; ULISSES, L. W. C.; CAMARA, T. R. Geração e desintoxicação enzimática de espécies reativas de oxigênio em plantas. Ciência Rural, v. 44, p. 453-460, 2014. http://dx.doi.org/10.1590/S0103-84782014000300011

BEAUCHAMP, C.; FRIDOVICH, I. Superoxide dismutase: improved assays and an assay applicable to acrylamide gels. Analytical Biochemistry, v. 44, p. 276-287, 1971. http://dx.doi.org/10.1016/0003-2697(71)90370-8

CARNEIRO, M. M. L. C.; DEUNER, S.; OLIVEIRA, P. D. de; TEIXEIRA, S. B.; SOUSA, C. P.; BACARIN, M. A. et al. Atividade antioxidante e viabilidade de sementes de girassol após estresse hídrico e salino. Revista Brasileira de Sementes, v. 33, p. 752$761,2011$.

CARNEIRO, M. M. L. C.; GOMES, M. P.; SANTOS, H. R. B.; REIS, M. V. dos; MENDONÇA, A. M. das C.; OLIVEIRA, L. E. M. de. Fotorrespiração e metabolismo antioxidante em plantas jovens de seringueira cultivadas sob diferentes fontes de nitrogênio $\left(\mathrm{NO}_{3}{ }^{-}\right.$e $\left.\mathrm{NH}_{4}{ }^{+}\right)$. Revista Brasileira de Ciências Agrárias, v. 10, p. 66-73, 2015. http://dx.doi.org/10.5039/agraria.v10i1a4941 
CANTO, T. do; PICH, C. T.; GEREMIAS, R. Bioensaio de toxicidade em percolados no aterro sanitário do município de Araranguá (Santa Catarina, Brasil). Revista Biociências, v. 19, p. 53-60, 2013.

CERQUEIRA, R. C.; COSTA, J. M.; CHAVES, M. M.; RODRIGUES, J. D. Fisiologia e metabolismo foliar em duas variedades de videira sujeitas a um ciclo de défice hídrico e reidratação. Revista Brasileira de Ciências Agrárias, v. 10, p. 211-217, 2015.

CHAI, Y. Y.; JIANG, C. D.; SHI, L.; SHI, T. S.; GU, W. B. Effects of exogenous spermine on sweet sorghum during germination under salinity. . Biologia Plantarum, v. 54, p. 145-148, 2010. http://dx.doi.org/10.1007/s10535-010-0023-1

COELHO, D. C. L.; BATISTA, R. O.; SILVA, P. C. M. da. MESQUITA, F. O. Produção de capim elefante utilizando percolado de aterro sanitário. Bioscience Journal, v. 31, p. 830-840, 2015. http://dx.doi.org/10.14393/BJ-v31n3a2015-22400

DEUNER, C.; MAIA, M. de S.; DEUNER, S.; ALMEIDA, A. da S.; MENEGHELLO, G. E. Variabilidade e atividade antioxidante de sementes de genótipos de feijão miúdo submetidos ao estresse salino. Revista Brasileira de Sementes, v. 33, p. 713-722, 2011.

DEUNER, S.; ALVES, J. D.; FRIES, D. D.; ZANANDREA, I.; LIMA, A. A.; HENRIQUE, P. de C. et al. Peróxido de hidrogênio e ácido ascórbico influenciando a atividade de enzimas antioxidantes de mudas de cafeeiro. Revista Ceres, v. 55, p. 135-140, 2008.

DUTRA, C. C.; PRADO, E. A. F.; PAIM, L. R.; SCALON, S. de P. Q. Desenvolvimento de plantas de girassol sob diferentes condições de fornecimento de água. Semina: Ciências Agrarias, v. 33, p. 2657-2668, 2012.

FOOD AND AGRICULTURE ORGANIZATION - FAO. World Food and Agricultura. Rome, 2013. 134 p.

GILL, S. S.; TUTEJA, N. Reactive oxygen species and antioxidant machinery in abiotic stress tolerance in crop plants. Plant Physiology and Biochemistry, v. 48, p. 909-930, 2010. http://dx.doi.org/10.1016/j.plaphy.2010.08.016

GONDIM, F. A.; MIRANDA, R. S.; GOMES-FILHO, E.; PRISCO, J. T. Enhanced salt tolerance in maize plants induced by $\mathrm{H}_{2} \mathrm{O}_{2}$ leaf spraying is associated with improved gas Exchange rather than with non-enzymatic antioxidant system. Theoretical and Experimental Plant Physilogy, v. 25, p. 251-260, 2012. http://dx.doi.org/10. 1590/S2197-00252013000400003

GHOBADI, M.; TAHERABADI, S.; GHOBADI, M.; MOHAMMADI, G.; JALALIHONARMAND, S. Antioxidant capacity, photosynthetic characteristics and water relations of sunflower (Helianthus annuus L.) cultivars in response to drought stress.

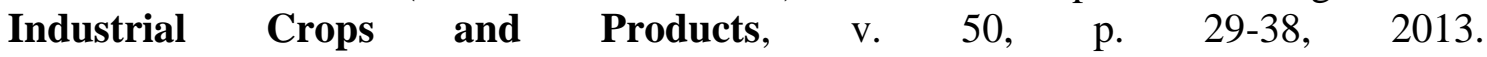
http://dx.doi.org/10.1016/j.indcrop.2013.07.009

GLOVATSKI; T. G. G.; RAIHER, A. P. A oferta de matérias primas (oleaginosas) do biodiesel no Brasil e seus determinantes: uma análise dos anos de 1991 a 2010. Estudo \& Debate, v. 20, p. 07-32, 2013. 
GOMES, K. R.; SOUSA, G. G. de; LIMA, F. A.; VIANA, T. V. de A.; AZEVEDO, B. M. de; SILVA, G. L. da. Irrigação com água salina na cultura do girassol (Helianthus annuus L.) em solo com biofertilizante bovino. Irriga, v. 20, p. 680-693, 2015. http://dx.doi.org/10.15809/irriga.2015v20n4p680

HAVIR, E.; McHALE, N. A. Biochemical and developmental characterization of multiple forms of catalases in tobacco leaves. Plant Physiology, v. 84, p.450-455, 1987. http://dx.doi.org/10.1104/pp.84.2.450

JADOSKI, C. J.; RODRIGUES, J. D.; SORATTO, R. P.; SANTOS, C. M. dos; RIBEIRO, E. Ação fisiológica da piraclostrobina na assimilação de $\mathrm{CO}_{2}$ e na atividade de enzimas antioxidantes em plantas de feijão em diferentes tensões de água no solo. Irriga, v. 20, p. 319-333, 2015. http://dx.doi.org/10.15809/irriga.2015v20n2p319

JALEEL, C. A.; MANIVANNAN, P.; WAHID, A.; FAROOQ, M.; AL-JUBURI, H. J.; SOMASUNDARAM, R. et al. Drought stress in plants: a review on morphological characteristics and pigments composition. International Journal of Agriculture \& Biology, v. 11, p. 1-6, 2009.

KANUNGO, M.; JOSHI, J. Impact of Pyraclostrobin (F-500) on crop plants. Plant Science Today, Trivandrum, v. 3, p. 174-178, 2014.

KAR, M.; MISHRA, D. Catalase, peroxidase, and polyphenoloxidase activities during rice leaf senescence. Plant Physiology, v.57, p.315-319, 1976.

http://dx.doi.org/10.1104/pp.57.2.315

KARUPPANAPANDIAN, T.; MOON, J.; KIM, C.; MANOHARAN, K.; KIM, W. Reactive oxygen species in plants: their generation, signal transduction, and scavenging mechanisms. Australian Journal of Crop Science, v. 5, p. 709-725, 2011.

MANIVANNAN, P.; JALEEL, C.A.; SANKAR, B.; KISHOREKUMAR, A.; SOMASUNDARAM, R.; LAKSHMANAN, G. M. A. et al. Growth, biochemical modifications and proline metabolism in Helianthus annuus L. as induced by drought stress. Colloids and Surfaces B: Biointerfaces, v. 59, p. 141-149, 2007. http://dx.doi.org/10.1016/j.colsurfb.2007.05.002

MILLER, G.; SUZUKI, N.; ÇIFTÇI-YILMAZ, S.; MITTLER, R. Reactive oxygen species homeostasis and signalling during drought and salinity stresses. Plant, Cell \& Environment, v. 33, p. 453-467, 2010. 10.1111/j.1365-3040.2009.02041.x

NAKANO, Y.; ASADA, K. Hydrogen peroxide is scavenged by ascorbate-specific peroxidase in spinash chloroplasts. Plant \& Cell Physiology, v. 22, p. 867-880, 1981.

NATIONAL SUNFLOWER ASSOCIATION. Sunflower sustainability: the substance behind the seed. 2010. Disponível em: https://goo.gl/lBTv19. Acesso em: 12 de mar. de 2016.

NOBRE, R. G.; GHEYI, H. R.; SOARES, F. A. L.; CARDOSO, J. A. F. Produção de girassol sob estresse salino e adubação nitrogenada. Revista Brasileira de Ciência do Solo, v. 35, p. 929-937, 2011. http://dx.doi.org/10.1590/S0100-06832011000300027 
PEREIRA, J. W. de L.; MELO FILHO, P. de A.; ALBUQUERQUE, M. B.; NOGUEIRA, R. J. M. C.; SANTOS, R. C. Mudanças bioquímicas em genótipos de amendoim submetidos a déficit hídrico moderado. Revista Ciência Agronômica, v. 43, p. 766$773,2012$.

REN, J.; SUN, L. N.; ZHANG, Q. Y.; SONG, X. S. Drought tolerance is correlated with the activity of antioxidante enzymes in Cerasus humilis seedlings. BioMed Research International, v. 2016, p. 1-9, 2016. http://dx.doi.org/10.1155/2016/9851095

SANTOS, D. dos; GUIMARÃES, V. F.; KLEIN, J.; FIOREZE, S. L.; MACEDO JÚNIOR, E. K. Cultivares de trigo submetidas a déficit hídrico no início do florescimento, em casa de vegetação. Revista Brasileira de Engenharia Agrícola e Ambiental, v.16, p. 836842, 2012. http://hdl.handle.net/11449/40463

SANTOS, J. C. C. dos; SILVA, C. H. da; SANTOS, C. S. dos; SILVA, C. de S.; MELO, E. B.; BARROS, A. C. Análise de crescimento e evapotranspiração da cultura do rabanete submetido a diferentes lâminas de água. Revista Verde de Agroecologia e Desenvolvimento Sustentável, v.9, p. 151-156, 2014.

SILVA, M. B. R.; FERNANDES, P. D.; NETO, J. D.; NERY, A. R.; RODRIGUES, L. N.; VIÉGAS, R. A. Crescimento e produção do pinhão-manso irrigado com água residuária sob condições de estresse hídrico. Revista Brasileira de Engenharia Agrícola e Ambiental, v. 15, p. 621-629, 2011. http://dx.doi.org/10.1590/S1415-43662011 000600013

SILVEIRA, J. A. G.; SILVA, S. L. F.; SILVA, E. N.; VIÉGAS, R. A. Mecanismos biomoleculares envolvidos com a resistência ao estresse salino em plantas. In: GHEYI, H. R.; DIAS, N. S.; LACERDA, C. F. (eds.). Manejo da salinidade na agricultura: estudos básicos e aplicados. 1. ed. Fortaleza: INCTSal. 2010. cap. 11. p. 161-185.

SCANDALIOS, J. G. Oxidative stress: Molecular perception and transduction of signals triggering antioxidant gene defenses. Brazilian Journal of Medical and Biological Research, v. 38, p.995-1014, 2005. http://dx.doi.org/10.1590/S0100-879X200 5000700003

SHARMA, P.; JHA, A. B.; DUBEY, R. S.; PESSARAKLI, M. Reactive oxygen species, oxidative damage, and antioxidative defense mechanism in plants under stressful conditions. Journal of Botany, v. 2012, p. 1-26, 2012.

http://dx.doi.org/10.1155/2012/217037

SHEHAB, G. G.; AHMED, O. K.; EL-BELTAGI, H. S. Effects of Various Chemical Agents for Alleviation of Drought stress in rice plants (Oryza sativa L.). Notulae Botanicae Horti Agrobotanici Cluj-Napoca, v. 38, p. 139-148, 2010.

WILLADINO, L.; OLIVEIRA FILHO, R. A.; SILVA JUNIOR, E. A.; GOUVEIA NETO, A.; CAMARA, T. R. Estresse salino em duas variedades de cana-de-açúcar: enzimas do sistema antioxidativo e fluorescência da clorofila. Revista Ciência Agronômica, v. 42, p. 417-422, 2011.

WULLSCHLEGER, S. D.; YIN, T. M.; DIFAZIO, S. P.; TSCHAPLINSKI, T. J.; GUNTER, L. E.; DAVIS, M. F. et al. Phenotypic variation in growth and biomass distribution for two advanced-generation pedigrees of hybrid poplar. Canadian Journal of Forest Research, v. 35, p. 1779-1789, 2005. http://dx.doi.org/10.1139/x05-101 
XAVIER, D. A.; FURTADO, G. de F.; SOUSA JÚNIOR, J. R. de; SOUSA, J. R. M. de; ANDRADE, E. M. G. Produção de fitomassa do milho sob lâminas de irrigação e adubação nitrogenada. Revista Verde de Agroecologia e Desenvolvimento Sustentável, v. 9, p. 144-148, 2014.

ZHANG, M.; DUAN, L.; ZHAI, Z.; LI, J.; TIAN, X.; WANG, B.; HE, Z.; LI, Z. Effects of plant growth regulators on water deficit-induced yield loss in soybean. In: INTERNATIONAL CROP SCIENCE CONGRESS, 4., 2004, Brisbane. Proceedings... Madison: Crop Science, 2004. Disponível em: https://goo.gl/gdIXmb. Acesso: 08 mar. 2016. 